\title{
El modelo democrático en México: entre la pre y la postmodernidad
}

\section{The democratic model in Mexico: between pre and postmodernity}

\author{
Henio Millán-Valenzuela*
}

\begin{abstract}
In México, social heterogeneity has historically raised up a dilemma between democracy and governability. In the past, this was solved through authoritarian solutions to guarantee governability. Now these solutions are impossible because the dominant presence of modern actors, who defend democracy. Nevertheless, the influence of pre and postmodern actors has made Mexican democracy leave the path of civic model of democracy, showing the restoration of an old balance among social actors, but now under the weakness of governability.
\end{abstract}

Keywords: democracy, heterogeneity, actors, pre-modernity, post-modernity.

\section{Resumen}

En México, la heterogeneidad social ha planteado históricamente un dilema entre gobernabilidad y democracia, en el pasado fue resuelto mediante soluciones autoritarias para salvaguardar la gobernabilidad, en la actualidad este tipo de salidas son imposibles, en virtud de la presencia dominante de los actores modernos que defienden la democracia; sin embargo, la influencia de los actores pre y postmodernos ha llevado a que, sin ser abandonada, la democracia siga una trayectoria que se aleja del modelo cívico clásico y que refleja la restitución del viejo equilibrio entre actores sociales, pero ahora al amparo del debilitamiento de la gobernabilidad.

Palabras claves: Democracia, heterogeneidad, actores, premodernidad, postmodernidad.

*El Colegio Mexiquense, A.c. Correo-e: hmillan@prodigy.net.mx 


\section{Introducción}

El Partido Revolucionario Institucional (PRI) perdió las elecciones para la presidencia de la república en el ańo 2000. Con este episodio emergieron las esperanzas de que México experimentara una vida democrática normal, muy cercana a la que viven los países desarrollados y los de transición reciente, pero exitosa. Hoy este régimen es objeto de múltiples críticas y descontentos, a pesar de la larga $-\mathrm{y}$ a veces dolorosa- lucha por instalarla como la única vía legítima para acceder al poder.

En el fondo, tal descontento expresa una crisis temprana de representatividad. Para mostrarla, estimé un indicador que se nutre de una encuesta levantada a nivel nacional, que fue diseñada por la Universidad Autónoma de Querétaro y por este autor, bajo el auspicio del Instituto Federal Electoral (IFE). Las entrevistas se realizaron quince días después de la elección de julio de 2009. Las preguntas inquieren, por un lado, sobre qué tanto les importa a las autoridades electas lo que piensan los entrevistados y, por el otro, qué tanto representan los partidos a los ciudadanos y qué tanto buscan su propio interés. Las respuestas fueron transformadas en una variable cuantitativa discreta, mediante el siguiente procedimiento: ${ }^{1}$

$$
V R_{i}=10-\left(L_{i}-1\right)^{*}\left(\frac{10}{n-1}\right)
$$

Donde vr es el valor de la respuesta i-ésima, que fluctúa entre 0 y 10 ; L, el lugar que ocupa la respuesta de mayor a menor, y n, el número de respuestas posibles.

Entonces para cada autoridad (o partido) j-ésima:

$$
I R_{j}=\frac{\sum_{i=0}^{10} f_{i j} * V R_{i}}{1200-D P}
$$

Donde IR es el índice de representatividad de la autoridad (o partido) j-ésima; f, las frecuencias o número de casos que asignaron la respuesta i-ésima a esa autoridad; VR, el valor de la respuesta i-ésima, y DP, los datos perdidos.

${ }^{1}$ Las respuestas fueron: totalmente, que recibe una calificación de 10; mucho, de 6.67; poco, de 3.33; nada, de cero. A menos que se indique lo contrario, toda la información proporcionada, incluida la de los cuadros, proviene de la encuesta mencionada que se puede encontrar en Ávila $e t$ al. (2010). 
Por otro lado, el índice de representatividad de las autoridades o de los partidos es un promedio simple de los índices:

$$
I R A o P=\frac{\sum_{j=1}^{m} R_{j}}{m}
$$

Donde IRAOP es el índice general de representatividad de todos las autoridades electas o de todos los partidos, y m, el número de autoridades electas o de partidos.

La representatividad también puede ser estimada en forma conjunta para autoridades y partidos, si incorporamos el valor de la respuesta a cada rubro con el que fueron juzgadas ambas instituciones:

$$
I G R_{i}=\frac{\sum_{j=1}^{k} V R_{i k}}{k}
$$

Donde IGR es el índice global de representatividad que le otorga conjuntamente el encuestado i-ésimo a partidos y autoridades; $\mathrm{k}$, los rubros calificados que incluyen tanto los de las autoridades como los de los partidos; vR, el valor de la respuesta que el i-ésimo encuestado le otorga a la autoridad o a la dimensión busca el interés de la gente o la correspondiente a representar a ciudadanos.

Así el índice global de representatividad para el conjunto de encuestados es:

$$
I G R=\frac{\sum_{i=1}^{1200} I G R_{i}}{1200}
$$

Los índices respectivos se mueven en una escala de 0 a 10 y sus estimaciones son presentadas en la gráfica 1 .

Como se puede apreciar, las autoridades electas y los partidos políticos exhiben índices no sólo reprobatorios sino también extremadamente bajos, cuando se les examina separada y conjuntamente.

Esta investigación está enfocada en mostrar que detrás de esta pálida representatividad se encuentra el conflicto estructural entre la democracia y la gobernabilidad, que se desarrolla cuando aquélla trata de desplegarse en un contexto de heterogeneidad social. Así lo atestigua la historia mexi- 


\section{Gráfica I \\ Índice de representatividad}

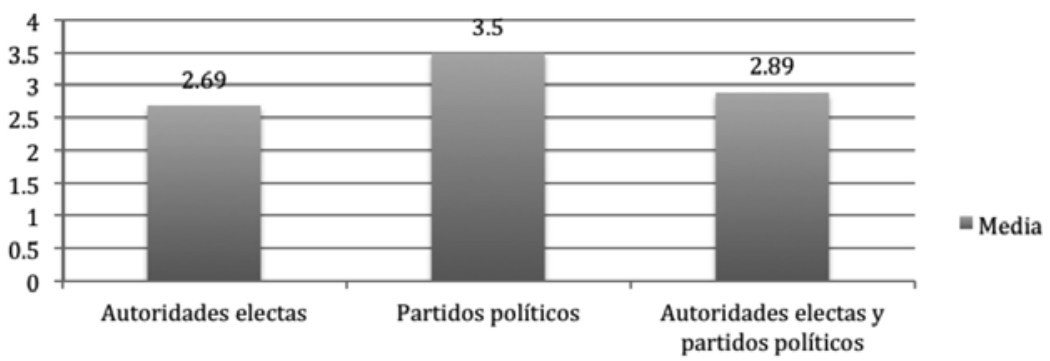

Fuente: Elaboración propia con base en la encuesta para elaborar el estudio de Ávila et al. (2010).

cana; sin embargo, a diferencia de lo que sucedió durante el siglo XIX y $\mathrm{xx}$, este dilema hoy no se ha resuelto mediante expedientes autoritarios, sino con desviaciones aparentemente irreversibles del modelo cívico de la democracia clásica. La causa de esta solución reside en tres factores a través de los cuales ahora opera la heterogeneidad: el agotamiento de los actores modernos, el resurgimiento de los colectivos o premodernos, y la alineación entre los intereses de estos últimos y las simpatías de un nuevo tipo de actor: el postmoderno.

Para mostrar estas hipótesis, el artículo se ha organizado en seis secciones: en la primera se elabora una tipología de los actores sociales, con el propósito de extraer y operativizar las variables que dan cuenta de su comportamiento; la segunda se encarga de describir y reinterpretar de forma resumida cuál ha sido su papel en la construcción histórica de la democracia nacional; la tercera indaga las causas del agotamiento de los actores modernos, principales impulsores de la democracia; la cuarta y la quinta se ocupan de la manera en que los actores premodernos y postmodernos, respectivamente, han contribuido a frenar o distorsionar la democracia mexicana, en su afán de frenar el proceso modernizador. Finalmente, se especifican las conclusiones a las que se llegaron con este análisis.

\section{Tipologías y heterogeneidad social: operativización de las variables $^{2}$}

Por heterogeneidad social entendemos la coexistencia de varios actores que se distinguen entre sí por sus distintos grados de modernidad en una línea discontinua que despega con los actores premodernos, prosigue con los modernos y termina con los postmodernos. Los saltos entre cada

\footnotetext{
${ }^{2}$ Esta tipología se basa en un trabajo previo que realicé con otros investigadores y que ha sido publicado en forma digital por el IFE: Ávila et al. (2010).
} 
categoría dependen de la importancia que asume la racionalidad para organizar la vida social y privada, especialmente cuando se trata de obtener recursos para satisfacer necesidades y deseos materiales o simbólicos. Por tal razón, la encuesta aludida inquirió sobre los factores que determinan el éxito y abrió las siguientes opciones: estudio, trabajo, cuna, suerte, amistades o relaciones personales, trabajar en lo que uno desea, y conocimiento de sí mismo. A partir de ahí, se construyen los tipos ideales:

i. El premoderno tradicional asume su condición como una fatalidad, éste es su rasgo distintivo. No existen los mecanismos que le permitan imaginar otra vida que la que se vive: pobres y ricos permanecen en la situación en la que nacieron, porque simplemente la movilidad no forma parte de la dinámica social. Cualquier esfuerzo es estéril para provocar mejorías en el bienestar, que no provengan de la suerte o que no estén atadas a las de la colectividad. Es ésta la que construye a los seres humanos como entidades culturales, porque suministra la protección frente a un escenario en permanente vulnerabilidad: la suerte determina el volumen de la cosecha o que el ganado no se muera de sed o hambre, por no mencionar los efectos de los desastres de la naturaleza. Supervivencia es el nombre del juego (Escalante, 1993), y ella demanda protección de la comunidad y una acentuada aversión al riesgo. Por tal razón, el trabajo adquiere una connotación simbólica y distinta a la instrumental (Polanyi, 2001): es esencialmente una de las tantas partes que conforman una economía consuntiva, ajena al lucro, y en la que los intercambios están orientados a la conservación de la unidad y cohesión del grupo, porque de ambas depende la protección frente a choques adversos y a riesgos incontrolables. Los individuos se funden en la comunidad y no hay vestigio de división entre lo público y lo privado. Las relaciones personales constituyen una parte sustancial de los intercambios sociales y contribuyen decididamente no sólo al afianzamiento de la cohesión, sino también a despojarlos de cualquier comportamiento oportunista: la confianza se construye mediante esas relaciones hasta relegar a un segundo plano el objeto de la transacción. Por ello, la importancia de los vínculos personales será un rasgo común a todo tipo de premodernidad.

Para operativizar la inmovilidad social se escogieron dos variables como factor de éxito: la cuna y la suerte. Si se es afortunado, ésta inclina la balanza hacia el nacimiento en una familia con una condición económica y social acomodada, si no es así, hacia una donde priva la penuria y una posición baja en la escala social. Pero 
también la suerte opera como una aproximación de la vulnerabilidad social: cuando sopla favorablemente, aumentan las cosechas, el ganado se reproduce y la naturaleza no se ensaña contra el grupo social, cuando no es así, la supervivencia puede verse en peligro. Por tanto, la cuna y la suerte constituyen los dos componentes que integran este tipo ideal.

ii. El premoderno rentista. El rasgo distintivo de este tipo es el privilegio, como forma de allegarse recursos materiales y simbólicos. Este tipo comparte con el anterior la importancia de las relaciones personales como eje de los intercambios sociales y la sumisión a un colectivo, que toma la forma de una estructura de redes sociales. Se diferencia en que la movilidad individual es posible, gracias a que el privilegio se convierte en una fuente de rentas desvinculadas de la productividad y muy asociada a la exclusión de otros grupos sociales: si es posible ingresar a las redes sociales mediante el aprovechamiento de las relaciones personales, se tendrá acceso a una porción de las rentas generadas y, por esta vía, mejorar la posición económica y social de partida.

Por tanto, el ámbito en el que este tipo de premodernidad se desenvuelve demanda dos condiciones: el aprovechamiento del privilegio para suscitar la generación de rentas y la inclusión en una red social para distribuirlas. Ambas dimensiones pueden derivar de una situación original, en la medida en que una cuna afortunada no sólo suministra directamente las actividades monopólicas o cuasimonopólicas, que en las que encarna el privilegio, sino también el conjunto de relaciones sociales que permiten acceder a esas ventajas exclusivas. Por tal razón, comparte con el premoderno tradicional la importancia de la cuna en el destino individual.

Sin embargo, la inclusión en las redes que medran del privilegio no está del todo vedada a otros miembros externos: bajo ciertas y variadas circunstancias, puede ser ampliada a individuos que, provenientes de otros círculos y condiciones sociales más depauperados, representan algún tipo de utilidad para los integrantes de la red. Y por utilidad debe entenderse una gama amplia de acepciones, que van desde la simple amistad hasta la connivencia para desmantelar cualquier tipo de cuestionamiento sobre la legitimidad del privilegio; por ello, no es extraño observar a personajes que a través de amistades con los privilegiados pudieron ascender económica y socialmente, o a líderes sociales capaces de intermediar entre las comunidades más pobres y el poder político hasta formar parte de él (Escalante, 1993), o a políticos que mediante sus con- 
tactos con la élite económica devienen empresarios usando el intercambio de favores para configurar y expandir su capital original.

Cualquiera de estas formas conduce a la configuración de vínculos personales, tejidos por acuerdos tácitos que rigen el intercambio de favores y la fidelidad entre los agentes. De esta manera, la solidaridad mecánica de la comunidad es transformada en capital social en el sentido de Bourdieu (1983): un conjunto de relaciones sociales que pueden usarse para el escalamiento económico y social. La pregunta que recurrentemente ha levantado esta visión es: por qué quien se encuentra en la situación privilegiada abre sus puertas al más débil (Lin, 2001); la respuesta es doble, incluye elementos extrarracionales que se centran en la actitud de ayudar a quien propicia un sentimiento de amistad, pero también incorpora componentes racionales que apuntan hacia el provecho que, en el largo plazo, puede obtenerse de un beneficiario con potencial para retribuir con creces el favor inicial.

Sin embargo, el componente más común es que el beneficiario acuse capacidades para proteger los privilegios y para expandir en el largo plazo el monto de las rentas. De esta forma, el premoderno rentista opera de la misma forma que un individuo moderno, al imitar sus intenciones maximizadoras; pero éstas apuntan hacia la obtención de rentas y no hacia las ganancias que derivan directamente de la actividad productiva. En este sentido, aunque el premoderno rentista es perfectamente compatible con formas precapitalistas, se desenvuelve de mejor manera en un sistema mercantil orientado al lucro, porque éste desarrolla más intensamente las fuerzas productivas y la productividad de los factores. La única condición es que tal esquema se rija por políticas mercantilistas que impidan la libre competencia y propicien una estructura de mercado mono u oligarquizada. De ser cierta esta hipótesis, la existencia del premoderno rentista supone, para su mejor desempeño, la existencia del capitalista moderno, que finca el éxito en el esfuerzo, aunque la relación inversa no se sostenga necesariamente.

Por las razones anteriores, las variables operativas que dan cuenta del tipo premoderno rentista son la cuna y un concepto amplio que resumimos con el término amistades, para denotar la inclusión en una red determinada.

iii. El moderno. El rasgo distintivo es el individualismo y la sujeción de la vida, privada y social, a la racionalidad instrumental. Es el primero que funda su existencia en el individuo y no en una figura colectiva: las teorías del contrato social, desde Hobbes hasta Rousseau, lo ubican en el origen de la sociedad, como una forma de 
superar un estado de la naturaleza, en la que la ausencia de un poder político se traduce en individuos atomizados y sin relaciones sociales significativas. Sus características fundamentales son, por ello, el individualismo y la racionalidad, ambos aspectos conducen a la constitución de un poder configurado por un pacto social que se traduce en el respeto a las leyes e instituciones garantizadas por un Estado fuerte, porque este marco regulatorio facilita la promoción de autointerés: tercera característica.

La cuarta particularidad es el liberalismo: el Estado, ya sea autoritario o democrático, está diseñado para servir al interés individual, o mejor, para conformar y hacer respetar un marco institucional que facilite la libre iniciativa individual, sin que ésta derive en una competencia que transgreda las libertades y derechos de las personas. Su intervención debe ser reducida al mínimo y constreñirse al ámbito estrictamente público.

Con la modernidad, asociada a la aparición del Estado y al surgimiento del capitalismo, las esferas públicas y privadas dejan de confundirse y son separadas en espacios legalmente distinguibles. La persona se desdobla en dos instancias: el ciudadano, que participa en el ámbito público, y el individuo, dedicado al privado, donde se despliegan dos tipos de actividades: familiares y productivas. La condición liberal impone que éste último espacio no debe ser rebasado por la injerencia estatal. Por ello, el bienestar está asociado única y exclusivamente al esfuerzo personal, éste constituye el expediente más eficaz para labrar y controlar su propio destino y, al mismo tiempo, el único elemento que debe regir la diferenciación social.

No obstante, la construcción del propio destino mediante el esfuerzo partía de una premisa que distaba de verificarse en el campo histórico: la igualdad original. En términos ideales, el liberalismo postulaba que todos los hombres son no sólo jurídicamente iguales, sino también dotados de las mismas capacidades, en virtud de que la razón se repartía de forma equitativa. Así se gesta la igualdad de oportunidades; su aprovechamiento dependía solamente del despliegue del esfuerzo personal; por tanto, la diferenciación de estas energías se constituía en el único sustento legítimo de la desigualdad social, pero en los hechos, existían otras fuentes de inequidad, como las herencias, el acceso a la educación y a la salud, que marcaban trayectorias biográficas muy disímiles, precisamente porque la igualdad de capacidades no se veía correspondida con la de oportunidades. Es entonces cuando el Estado de bienestar, bajo cualquiera de sus modalidades (Esping-Andersen, 
1990), rompe con el paradigma clásico liberal para equiparar de forma permanente las oportunidades.

Pero también bajo este paradigma se sostiene la importancia del esfuerzo como divisa de autorrealización individual: enseñar a pescar es prioridad frente a la dádiva del pescado, porque empareja oportunidades para que los individuos puedan valerse por sí mismos, después del apoyo temporal del Estado. Cualquier otro camino distinto conduce a una injerencia más cercana al populismo que al Estado del bienestar, figura tan moderna como su adversario liberal.

Por ello, el liberalismo no es una condición de la modernidad, como tampoco lo es la democracia. Este tipo de régimen es el que mejor se acomoda a las aspiraciones de los actores modernos, porque representa la mejor vía para controlar un poder político que, eventualmente, puede impulsar derechos de propiedad que estimulen la extracción de rentas (North, 1989). En este caso, la consecuencia no puede ser otra que una parte del esfuerzo productivo no se traduzca en bienestar. Por tal razón, la democracia es vista como una forma de controlar el poder y de sujetarlo a leyes emanadas de los representantes de los propios ciudadanos. Sin embargo, el Estado autoritario - por ejemplo, el Estado absoluto- puede ser aceptado por los actores modernos cuando se trata de desplegar la batalla contra los privilegios y rentas de los actores premodernos.

Nos parece que todas las características se funden en la defensa de los mecanismos que permiten traducir el esfuerzo en bienestar individual. En la medida en que éste suele ser el termómetro del éxito, podemos asociarlo con el esfuerzo construido con dos variables emblemáticas: el trabajo y el estudio. Ambas han sido concebidas para prosperar, la primera, mediante un aumento del producto; la segunda, de la productividad: la combinación clásica entre dotación y eficiencia de factores de las funciones típicas de producción.

iv. El postmoderno. Acusa como rasgos centrales el hiperindividualismo y el hedonismo. El primero enfatiza no sólo el individualismo en un grado extremo, sino también y especialmente, el relativismo ético que amolda cualquier principio moral a la conveniencia e intereses del sujeto, con el propósito de legitimar todas las elecciones de vida personal y casi cualquier acción destinada a desprenderse fácilmente de situaciones que comprometan la libertad y la soberanía individual. En este sentido, la postmodernidad representa una acentuación de la modernidad. 
De esta característica deriva el intento por recuperar la diversidad social y cultural, como una extensión de la legitimación de la variedad de biografías personales: si es válido que cada quién escoja la vida que quiere vivir, también lo es que los pueblos y las sociedades opten libremente por figuras asociativas y culturales que son afines a sus tradiciones y a sus propias identidades, y que éstas sean tan diversas y respetables como lo son las personalidades individuales. En consecuencia, el actor postmoderno se opone firmemente a los afanes uniformizadores de la modernidad y tiende, por tanto, a identificarse con uno de los aspectos más importantes del premoderno tradicional: la defensa de la especificidad y particularidad.

Pero la característica más importante del actor postmoderno es la centralidad que en sus aspiraciones ocupa el hedonismo. Este es el impulso que organiza de manera más sentida y permanente sus acciones. Por ello, la cultura del esfuerzo pierde el valor que tenía en la modernidad: ningún sacrificio vale la pena, precisamente porque resta al presente la oportunidad de gozar otras opciones; pero también porque significa una desutilidad, es decir, una insatisfacción, que difícilmente cubre cualquier remuneración, en contra de lo que postulaba el pensamiento neoclásico de la economía. Para el postmoderno no existe prácticamente un emolumento que pague la insatisfacción de trabajar. Por ello, el trabajo deja de ser un valor y sólo es atractivo cuando se despliega en actividades que uno haría aún sin un salario; es decir, en lo que le gusta. Por tal razón, la primera variable para construir este tipo ideal es trabajar en lo que a uno le gusta como determinante del éxito.

La otra dimensión de la cultura del esfuerzo es el estudio; también la hemos incorporado porque para una buena parte de los postmodernos esta actividad es no una vía para elevar la eficiencia productiva, sino que está orientada al placer por el conocimiento, que puede incluso redituar en labores placenteras como las académicas, y que redirigido hacia el ego, conduce al conocimiento de sí mismo: una forma distinta de expresar el hiperindividualismo.

El trabajo por gusto, el estudio por placer y el conocimiento de sí mismo son acciones que tienen en común el crepúsculo del deber, para usar la frase afortunada de Lipovetsky (2002). Ninguna de ellas implica un compromiso de largo plazo (Sennett, 2000) y puede ser abandonada sin consecuencias graves para futuro del individuo. Mientras el moderno se esfuerza por construir el futuro individual y familiar, para el postmoderno el futuro no existe -como llegó a postular la generación $\mathrm{X}-\mathrm{o}$ no vale la pena sacrificarse por él; 
mientras el primero pretende controlar su destino, el postmoderno renuncia a esta tarea y se sume en el mundo de la incertidumbre. Por tal razón, reintroducimos la variable suerte como factor de éxito, de forma coincidente con el premoderno tradicional.

\section{Los actores sociales en la construcción de la democracia}

En el caso de México, los actores modernos pueden rastrearse desde la Colonia, y su irrupción en la historia nacional no ha dejado imprimir su huella, a pesar de que -salvo en épocas recientes- representaron una fracción muy limitada de la población; sus intentonas de modernización han tropezado con reacciones de los componentes más profundos e históricos del conglomerado social, encarnados en figuras corporativas que han incluido desde las comunidades indígenas y el clero, hasta el ejército -en el siglo XIX- y organizaciones gremiales dependientes del Estado: a las reformas borbónicas del siglo XVIII le siguió una verdadera revolución de independencia, única en el continente americano; a la Reforma y al Porfiriato, la Revolución mexicana, y al proyecto de Salinas de Gortari, la revuelta zapatista de los años noventa en el estado de Chiapas.

Quizás sea Womack quien resume mejor este conflicto entre tradición y modernidad. La primera frase de su texto sobre Zapata dice: "Este es un libro acerca de unos campesinos que no querían cambiar y que, por eso mismo, hicieron una revolución" (Womack, 1979: xI). En ella se vislumbran las dificultades para emprender cambios -especialmente los modernizadores, como los que abanderaba el liberalismo porfirista-, sin arriesgar el orden y la estabilidad.

Los liberales del siglo XIX, tras cruentas guerras de Reforma y la intervención francesa, surgieron como una élite vencedora y, aparentemente, sin enemigos para instalar su proyecto democrático y la lógica capitalista como una realidad nacional. La abolición de los fueros, el carácter laico del Estado, la negación a reconocer la propiedad de cuerpos (comunidades indígenas, clero y ejército) constituían un arsenal jurídico, plasmado en la Constitución de 1857 y en las Leyes de Reforma, orientado a la construcción del Estado nacional y a la activación del capitalismo. Sin embargo, los intentos de aplicación generaron revueltas constantes entre campesinos o movimientos acicateados por el clero y fracciones del ejército. La solución de los liberales -particularmente el régimen de Porfirio Díaz-fue dejar en letra muerta buena parte de esas disposiciones legales. Con ello, se gestionó el orden tan ansiado y la paz, tras más de medio siglo de inestabilidad y conflictos bélicos continuos.

Sin embargo, el significado histórico de este tipo de soluciones fue la permanente separación entre la ley y los hechos. La democracia sufría una 
de sus principales derrotas, en términos de una sociedad regida por el Estado de Derecho. Pero este divorcio entre la legalidad y justicia en el fondo denunciaba un equilibrio entre actores modernos y premodernos que hizo posible la construcción de un Estado Nacional, condición necesaria pero insuficiente para hacer de la democracia un arreglo político y social que trascendiera la declaración legal.

La necesidad de construir el Estado era un imperativo de primer orden. La ausencia de un monopolio de la violencia legitima y la dispersión del poder en una multiplicidad de instancias locales, gremiales y sociales, le habían costado a México la mitad de su territorio. Para realizar esta tarea, los liberales y el Porfiriato debieron soslayar su proyecto democrático, pero sin modificar las leyes que lo expresaban: en lugar de federalismo, la construcción estatal demandó la eliminación y subordinación de los poderes locales; en vez de una república en la que los tres poderes se contrapesan, la concentración del poder en el ejecutivo y la subordinación del legislativo y el judicial devinieron piezas claves de la conformación del Estado. Si bien las elecciones continuaron y cumplieron con los requisitos legales, no tardaron en caer bajo control de las autoridades que, en los hechos, impedían la asunción de un partido opositor.

Si uno contrasta este paisaje con el que se dibujó tras el triunfo de la Revolución, los trazos son esencialmente los mismos. Los revolucionarios encararon el problema de la construcción del Estado mediante un esquema similar, que acabó relegando los procesos electorales a un mero ritual formal, al tiempo que el manejo discrecional de la ley fue un instrumento no sólo de poder, sino también, y sobre todo, un expediente para atender los particularismos de una sociedad heterogénea y, por ello, inatendible bajo formas uniformadoras cercanas al modelo cívico democrático-neoliberal.

Pero existía una diferencia crucial: los actores colectivos fueron organizados e incorporados al Estado mediante esquemas corporativos en la etapa definitiva de su construcción. La sociedad entera quedó seccionada en corporaciones, aglutinadas en el partido oficial; incluso los empresarios, que fueron excluidos de la filiación grupal al PRI, no escaparon a esta mecánica porque la llamada Ley de Cámaras obligaba a todo emprendedor a pertenecer a una agrupación patronal. El encuadramiento era fundamental para gestar el orden, evitar que la lucha de clases se desbordara y para guardar el equilibrio entre los factores de la producción; pero, además, se constituyó en el único conducto de comunicación entre gobierno y gobernados, fuera de él no había posibilidades de hacer política. El corporativismo dañaba el proyecto democrático por la vía de anular la existencia de los individuos y, por ello, de los ciudadanos. 
La industrialización, la urbanización y el crecimiento económico que México experimentó a partir de los cuarenta acarrearon la diversificación de la estructura económica y social. Con ella nacieron y se desarrollaron las clases medias, un agente difícilmente corporativizable. La consecuencia sería crucial para la revitalización del proyecto modernizador y el avance de la democracia mexicana, por varias razones: en primer lugar, con ellas aparece el individuo y, por tanto, un potencial ciudadano, fundamento de la democracia; en segundo término, por ser difícilmente corporativizables, aportaron el ingrediente para que la política pudiera discurrir por canales alternativos a los oficiales, sin los cuales es inconcebible la democracia; en tercer lugar, su lógica meritocrática representaba una confrontación permanente contra el carácter patrimonialista del Estado, asociado al propio corporativismo y al presidencialismo mexicano; por último, su emergencia significó la aparición de la opinión pública, o precisamente, porque esos estratos medios devinieron el núcleo dinámico de esa opinión (Millán, 1998) y, por ello, en una de las fuentes de consenso del Estado, que siempre estaría en pugna con la que le suministraba su alianza con las masas corporativizadas.

Fueron estas clases medias las que emprendieron los movimientos democráticos y modernizadores en el México contemporáneo. Fueron ellas las que apuntalaron el movimiento estudiantil de 1968, con sus demandas antiautoritarias; pero no es hasta los setenta cuando muestran su verdadera fuerza, al aliarse con las clases empresariales ante la expansión del Estado de los gobiernos de Echeverría y de López Portillo. Esta alianza logró cimentar en la opinión pública no sólo la idea de que las crisis obedecían al excesivo gasto público, la corrupción y la ineficiencia del Estado, sino también dos creencias fundamentales: la solución económica implicaba el abandono del modelo sustitutivo de desarrollo y la adopción de una política neoliberal; pero también que el excesivo intervencionismo estatal en las esferas sociales, sobre todo en la productiva y financiera, obedecía a caprichos del ejecutivo, posibilitados por el carácter autoritario, antidemocrático, corporativo y presidencialista del sistema político mexicano.

Tanto los empresarios como las clases medias se encargaron de impulsar modificaciones en la legislación electoral y, en términos generales, en los procesos políticos, apuntando hacia una mayor apertura y hacia la normalidad democrática del país.

Esta lucha, sin embargo, estaba hermanada con el cambio del modelo de desarrollo y la instalación de una política neoliberal, menos injerencista en la economía; primero llegó ésta, después, la democracia. Esta dualidad explica que la alternancia desembocara en un gobierno de derecha, a pesar de que en 1988 la izquierda mexicana había representado el 
primer gran reto a esa política económica al triunfar en unos comicios fraudulentos que le arrebataron el triunfo.

Fue esta alianza entre empresarios y estratos medios la que aportó las nuevas fuentes de consenso a los gobiernos neoliberales, incluidos los de la era democrática. Se produce así un cambio drástico en las bases consensuales del Estado: éstas se desplazan de las masas corporativizadas hacia segmentos sociales con un claro perfil moderno. Así parecía triunfar el proyecto de los actores modernos sobre los premodernos. Dos datos confirman este triunfo: la composición demográfica y el grado de modernidad (gráfica II).

\section{Gráfica II}

\section{Composición de los ciudadanos mexicanos por tipo de actor}

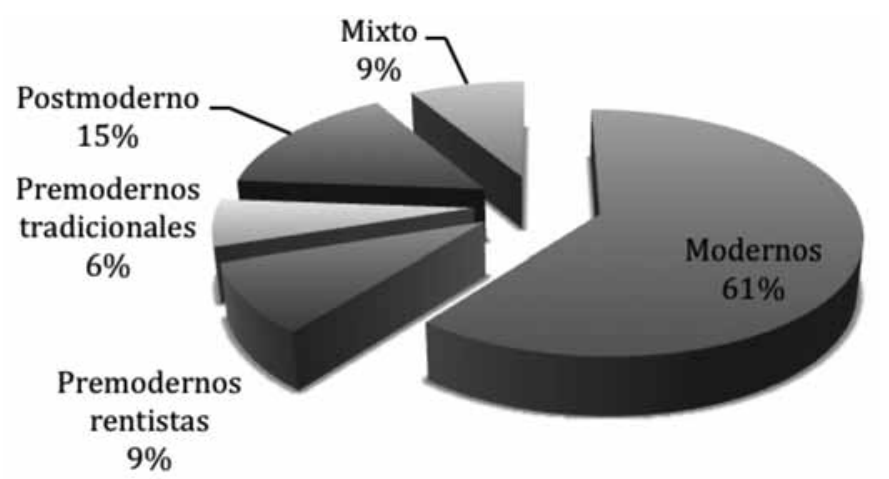

Fuente: Elaboración propia con datos de la encuesta para elaborar el estudio de Ávila et al. (2010).

Si medimos el grado de modernidad mediante un procedimiento similar al descrito anteriormente, pero en el que se le pide al encuestado que ubique el lugar del estudio y del trabajo en el éxito personal, la ecuación (1) se transforma en:

$$
V R_{i}=10-\left(L_{i}-1\right) *\left(\frac{10}{n}\right)
$$

El promedio simple de valor del estudio y del trabajo es el valor que el encuestado asigna al esfuerzo, variable operativa de la modernidad. El resultado es una escala que fluctúa entre 2.15 y 9.29. Si los valores se estratifican por el método Dalenius ${ }^{3}$ se obtienen los siguientes rangos:

${ }^{3}$ Una breve explicación de este método se puede encontrar en la página del inegi: http://www1. inei.gob.pe/biblioineipub/bancopub/est/lib0385/anex13.htm. 


\begin{tabular}{crl}
\hline \multicolumn{2}{c}{ Rangos de modernidad } & \\
\hline 2.15 & 4.292 & Muy baja \\
4.292 & 6.434 & Baja \\
6.434 & 7.148 & Media \\
7.148 & 8.576 & Alta \\
8.576 & 9.29 & Muy alta \\
\hline
\end{tabular}

La media de este indicador del grado de modernidad es de 7.5, que corresponde a una modernidad alta. De esta forma, los datos históricos y los relativos a la composición social y al grado de modernidad avalan el hecho de que la mexicana es una sociedad fundamentalmente moderna.

Sin embargo, la realidad actual revela que este triunfo de los modernos sobre los premodernos está limitado por el agotamiento de los primeros, la resurrección de los segundos y la creciente importancia de un nuevo tipo de actor: los postmodernos.

\section{El agotamiento de los actores modernos}

Ni el neoliberalismo ni la democracia pudieron desmontar los viejos privilegios y la obtención de rentas. La liberación de la economía se desplegó sobre estructuras mono u oligopólicas, que acabaron por acentuar la heterogeneidad estructural; las viejas corporaciones, si bien cada vez más prescindibles para la legitimidad del régimen, fueron capaces de defender los privilegios, especialmente después de la alternancia, en virtud de que al abandonar el PRI la presidencia de la república, éste quedó sin una jefatura visible capaz de subordinar y apaciguar los impulsos corporativos ante reformas que pretendían acabar con ese esquema de privilegios. La pérdida del poder en el año 2000 rompió una de las piezas claves del sistema político mexicano: la triple jefatura que ejercía el ejecutivo sobre el Estado, el gobierno y el partido.

La consecuencia no fue otra que una refeudalización, si entendemos por ella la tendencia de agrupaciones políticas a no obedecer a un poder centralizado. Así, el poder se ha vuelto a dispersar en gobernadores autónomos y organizaciones que tienen legitimidad propia para ejercer lícitamente varias formas de violencia en nombre de intereses grupales revestidos de movimientos populares que cuentan con la fuerza suficiente para frenar el proceso de modernización. Las manifestaciones más evidentes de este fenómeno son las movilizaciones que obstaculizan las aplicaciones de los decretos presidenciales, pero sobre todo las acciones del legislativo que paralizan o distorsionan las iniciativas tendentes al desmantelamiento de la estructura de privilegios asociadas a actores premodernos rentistas. 
Este freno ha sido uno de los factores más importantes del agotamiento democrático y de sus principales impulsores -los actores modernos-, porque impide el desvanecimiento de la anomia que desvincula el esfuerzo y el bienestar, sobre la cual reposaron el viejo sistema político y su esquema de redes personales, a través del cual se distribuían rentas y privilegios. Su permanencia los ha convencido de la esterilidad de la democracia y de que, en esencia, las cosas siguen igual que antes.

A este factor se suman otros dos de igual envergadura: el fracaso del modelo neoliberal para generar bienestar a esos actores y el ensimismamiento de los partidos políticos. La liberación de la economía acarreó la desaparición de numerosas empresas, sin que el impulso exportador hubiera sido lo suficientemente fuerte y amplio para contrarrestar la penetración de importaciones (Millán, 1997). Con ello, no sólo se ha debilitado el ritmo de crecimiento económico, sino también las oportunidades de reclutar en los cuadros administrativos a los profesionistas de las clases medias. Cuando se inspecciona la composición del desempleo mexicano, uno puede percibir una tendencia -también anómica- que atenta contra la divisa meritocrática: a mayor nivel de instrucción, mayor es la tasa de desempleo. A pesar del avance democrático y de la liberalización económica, la vinculación entre esfuerzo y bienestar se diluye. En este sentido, uno de los objetivos más deseados por los actores modernos parece más alejado y sin esperanza de ser retomado por la actual democracia mexicana.

Artífices de las reformas electorales, los partidos políticos han aprovechado el papel que han tenido en esa manufactura para establecer un diseño institucional cerrado a otras opciones políticas y orientado a un cuasimonopolio del poder político, mediante la imposición de umbrales electorales altos y, sobre todo, de la prohibición de candidaturas independientes y de la reelección inmediata de legisladores. De esta forma, el ciudadano enfrenta un espectro político cada vez más homogéneo, si atendemos a la conducta real y efectiva de los partidos, que propende a una mimetización en tres partidos distintos y un solo perfil verdadero.

Este diseño institucional ha estructurado un conjunto de incentivos en los que el porvenir de un político determinado depende menos de los electores que de las jerarquías de su partido. La disciplina partidaria se impone sobre un legislativo en el que cada vez recae más el poder político, a costa del tradicional presidencialismo mexicano. Sin embargo, esta dependencia ha menguado significativamente la influencia que la opinión pública tenía sobre el consenso y que se reveló como uno de los pivotes más importantes de la transición y del abandono del régimen autoritario. Por ello no es casual que tras escándalos políticos resonantes, los políticos permanezcan en sus puestos o salgan inmunes de las críticas y, a menudo, 
de la acción de la justicia. Un político puede ser captado por las cámaras de televisión recibiendo cantidades ingentes de dinero, y no pasa nada; se pueden difundir las conversaciones de un gobernador con un empresario local en plena confabulación para usar arbitrariamente la justicia contra una periodista, y el gobernador sigue en su encargo; un presidente de un partido ecologista puede ser captado por los micrófonos negociando prebendas monetarias a cambio de gestionar asentamientos en zonas acuíferas vedadas, y tanto su partido como su liderazgo quedan inmunes. La clase política se ha vuelto autorrefenciada.

En este sentido, los actores modernos han perdido uno de sus principales instrumentos de presión: la condena de la opinión pública. Esto es posible gracias a que esos escándalos se encuentran normalmente distribuidos y salpican a la totalidad de los partidos políticos. El costo en votos se reparte de manera similar y, por ello, las ventajas y desventajas tienden a mantenerse.

Sin el instrumento de la condena pública, los actores modernos se han visto desprovistos de su principal arma para presionar por el avance democrático y para orientar la actuación de los políticos. Así, la fuerza propulsora de la democracia parece extenuarse ante la impotencia de sujetar a esta élite al control ciudadano, como lo han demostrado -más formalmente- algunos modelos de agencia aplicados a la accountability mexicana (Millán y Natal, 2008).

Con el propósito de suministrar evidencia empírica a este agotamiento de los actores modernos, elaboramos un conjunto de indicadores con procedimientos similares descrito para la modernidad y la representatividad, y los vinculamos con la probabilidad de abstenerse electoralmente, ${ }^{4}$ como una aproximación de ese agotamiento. El procedimiento puede describirse de la siguiente manera:

$$
\ln \frac{P}{1-P}=\beta_{0}+\beta_{1} X_{i}
$$

Donde $\mathrm{P}$ es la probabilidad de abstenerse y, por tanto, 1-P es la probabilidad de votar; $\mathrm{X}$ es una variable independiente que determina o predice esa probabilidad, y el conjunto de $\beta$ representan los parámetros correspondientes. Por otro lado, ln es el logaritmo natural.

Con el fin de determinar la probabilidad de abstenerse para cada variable, adoptamos el siguiente procedimiento:

\footnotetext{
${ }^{4} \mathrm{~A}$ menos que se indique lo contrario, la escala de cada indicador es de 0 a 10 . Por razones de espacio, así como para no desviar la lectura, la exposición de la forma en que fueron construidos los índices de las variables independientes se remitió al apéndice de este artículo.
} 


$$
\begin{aligned}
& \operatorname{Exp}\left(\ln \frac{P}{1-P}\right)=e^{\left(\beta_{0}+\beta_{1} X_{i}\right)} \\
& \frac{P}{1-P}=e^{\left(\beta_{0}+\beta_{1} X_{i}\right)} \\
& P=(1-P)\left(e^{\left(\beta_{0}+\beta_{1} X_{i}\right)}\right) \\
& P=e^{\left(\beta_{0}+\beta_{1} X_{i}\right)}-P e^{\left(\beta_{0}+\beta_{1} X_{i}\right)} \\
& P+P e^{\left(\beta_{0}+\beta_{1} X_{i}\right)}=e^{\left(\beta_{0}+\beta_{1} X_{i}\right)} \\
& P\left(1+e^{\left(\beta_{0}+\beta_{1} X_{i}\right)}\right)=e^{\left(\beta_{0}+\beta_{1} X_{i}\right)} \\
& P=\frac{e^{\left(\beta_{0}+\beta_{1} X_{i}\right)}}{1+e^{\left(\beta_{0}+\beta_{1} X_{i}\right)}}
\end{aligned}
$$

Los resultados para cada determinante que resultó significativo se consignan en el cuadro que se muestra a continuación:

\section{Cuadro 1}

\section{Probabilidad media de abstenerse por determinante}

\begin{tabular}{lccc}
\hline & $\begin{array}{c}\text { Probabilidad media } \\
\text { de abstenerse }\end{array}$ & $\begin{array}{c}\text { Sentido de } \\
\text { la relación }\end{array}$ & $\begin{array}{c}\text { Media del } \\
\text { determinante }\end{array}$ \\
\hline Pobreza & $(\%)$ & & \\
Alimentaria & 24.39 & + & $37^{* * *}$ \\
Capacidades & 24.15 & + & $38^{* * *}$ \\
Patrimonial & 23.52 & + & $44^{* * *}$ \\
Escolaridad & & & \\
Ingreso medio & & & \\
Ingreso alto & 73.7 & + & 10.5 \\
General & 16.3 & - & 12.2 \\
Modernización & 22 & - & 9.7 \\
Confianza & 32.1 & - & $7.5^{*}$ \\
Representatividad & 21.2 & - & 3.9 \\
Autoridades y partidos & & & \\
Autoridades & 22 & - & 2.88 \\
Partidos & 22.2 & - & 2.69 \\
Déficit en la gestión gubernamental & 23.8 & - & 3.5 \\
Identificación Partidaria & 34 & + & $0.3^{* *}$ \\
General & & & \\
$\quad$ PAN & 21.2 & - & 2.87 \\
PRI & 21.8 & - & 3.7 \\
Sofisticación del votante & 21.2 & - & 3 \\
\hline
\end{tabular}

*Escala de 2.15 a 9.9

** Escala de -2 a 1

*** $\%$ de la línea de pobreza

Fuente: Elaboración propia con datos de encuesta para elaborar estudio de Ávila et al. (2010). 
Además de la baja representatividad de la élite política, resaltan dos datos adicionales: el bajo nivel de confianza en las instituciones y la relación positiva entre escolaridad y abstención para los ingresos medios, que muestra elocuentemente el divorcio entre esfuerzo y bienestar que ha acarreado la suspensión del proceso de modernización. Para reforzar estos datos, exhibimos la aglutinación de los determinantes por el método de componentes principales (cuadro 2).

\section{Cuadro 2 \\ Matriz de componentes rotados}

\begin{tabular}{lccc}
\hline & \multicolumn{3}{c}{ Componente } \\
& 1 & 2 & 3 \\
\hline Déficit de desempeño gubernamental & .120 & -.440 & .359 \\
Años totales de estudio & -.432 & .258 & .429 \\
Promedio individual de confianza & -.032 & .823 & .012 \\
Índice de sofisticación & -.137 & .199 & .624 \\
Índice de modernidad & -.039 & -.071 & .682 \\
Identificación partidaria promedio & .084 & .532 & .228 \\
Índice global de representatividad & -.119 & .802 & .044 \\
Brechas de la pobreza alimentaria & .990 & -.027 & -.071 \\
Brechas de la pobreza de capacidades & .990 & -.027 & -.071 \\
Brechas de la pobreza patrimonial & .990 & -.027 & -.071 \\
\hline
\end{tabular}

Método de extracción: Análisis de componentes principales. Método de rotación: Normalización Varimax con Kaiser.

La rotación ha convergido en cinco iteraciones.

Fuente: Elaboración propia con datos de Ávila et al. (2010).

El método extrae tres factores o dimensiones sobre los que cargan los demás: el primero se refiere claramente al componente pobreza; el segundo, a la crítica a la élite política, y el tercero, a la modernidad. Los dos últimos se refieren a los dos argumentos que hemos esgrimido para demostrar las fuentes de agotamiento de los actores modernos: el carácter autorreferenciado de los políticos y la sensación de que la modernización se ha detenido sin desvanecer la anomia entre esfuerzo y bienestar.

\section{Resurrección de los actores premodernos}

Al transitar al modelo secundario exportador, el Estado mexicano se fincó en un pacto social más restringido y oligárquico que el que caracterizó al Estado de la Revolución mexicana. Ahora sus apoyos provenían crecientemente de los estratos medios y de los sectores empresariales, mientras que las masas populares tendían a ser excluidas del mismo. Así el nuevo pacto social surgió como una primera condición -necesaria, pero 
no suficiente- para la autonomización de los actores colectivos, una de las vertientes más importantes de los segmentos premodernos. La segunda fue la alternancia en la presidencia de la república.

El nuevo contrato social parecía entonces ser tan estable como el cardenista, que suministró su fisonomía a la hegemonía priista. Esta creencia estaba sustentada en que el dominio estatal sobre los actores colectivos, especialmente los que anidaban corporativamente en el seno del partido oficial, permanecería inalterado frente al avance modernizador y democrático.

Sin embargo, el supuesto resultó ser falso: la alternancia acarreó consigo el debilitamiento del Ejecutivo y desplazamiento del poder hacia el Legislativo y, por esta vía, hacia los partidos políticos y los gobiernos locales. La base de ambos fenómenos residió en dos mecanismos simultáneos que minaron los fundamentos del viejo sistema político mexicano: la pérdida de las facultades metaconstitucionales del Ejecutivo federal y la ausencia de un jefe claro e indiscutible del partido oficial, en el que se aglutinaban los sectores populares premodernos. A través de estos expedientes, el sistema posibilitaba la subordinación de poderes fácticos y formales a la presidencia de la república.

Las consecuencias pueden dividirse en dos grupos: las relacionadas con la distribución del poder y las que atentan de forma estructural el funcionamiento de la democracia: las primeras refieren a la autonomización y dispersión de los poderes y la autorreferenciación de la élite política; las segundas, con la imposibilidad de avanzar tanto en el proceso de modernización como en el de democratización de las instituciones.

\subsection{Autonomización y dispersión de los poderes}

La construcción del Estado tras los dos hechos traumáticos que marcaron los siglos xIx y xx -la Guerra de Reforma y la Revolución-, enfrentaron, en ambos, la tarea de configurar el monopolio de la violencia legítima después del triunfo militar. En los dos eventos ese proceso demandó la subordinación de movimientos populares y la eliminación o sujeción de liderazgos políticos locales (Roeder, 1973); pero en el caso postrevolucionario fue posible mediante el encuadramiento de las masas al partido oficial (Córdova, 1973), que dotó al presidente de la república de un poder considerable para usarlo contra cualquier regateo desde el ámbito local y para determinar las carreras de todo aquel que aspiraba a ser alguien en la política mexicana, incluidas la de los líderes sindicales, campesinos y populares.

Cuando el PRI pierde la presidencia de la república, los poderes sociales y locales recuperan su autonomía. Los líderes populares dependen 
crecientemente de los apoyos de sus bases y, por ello, de su capacidad para defender causas antiguamente administradas desde el Estado; los gobernadores, de su potencial para influir en dos ámbitos nacionales: los partidos políticos y, sobre todo, en el Legislativo federal, que a diferencia del pasado ya no responde a los designios del Ejecutivo federal.

La autonomía de los movimientos populares en la época democrática los ha habilitado para vender y negociar sus lealtades a cualquier opción partidista, a cambio de la defensa de sus privilegios. Quizás el caso más notorio lo represente el Sindicato Nacional de Trabajadores de la Educación (SNTE), afiliado al PRI desde sus orígenes, pero que no tuvo escrúpulos de apoyar al candidato panista en las elecciones del 2006, a cambio de neutralizar la reforma educativa que tanto necesita el país. Pero quizás lo más importante sea que tal autonomía ubica a los líderes en la posición obligada de defender causas populares en la plataforma nacional, sean o no de su estricta competencia. El enemigo favorito son las reformas estructurales a favor de la modernización, a las que se asocia con el neoliberalismo, que muchas veces lo que efectivamente pretenden es el desmoronamiento de privilegios gestados al calor de la negociación que posibilitó el encuadramiento corporativo al antiguo partido oficial.

El campo fértil lo otorga un sentido de justicia, añejado desde la colonia, que desconfía de la iniciativa individual y que es abonado por la inequidad y la pobreza que campea en el país. Ese es el sentido de la primera componente del cuadro 2 .

Al desplegarse en un marco de heterogeneidad estructural, la política neoliberal tuvo efectos desiguales y propensos a favorecer a los que ya eran los más fuertes en el antiguo modelo de desarrollo. Aunque la pobreza ha descendido a partir de 1997, la distribución del ingreso permanece tan inequitativa como siempre, pero ahora en un contexto de muy bajo crecimiento económico y un PIB per cápita prácticamente estancado. Este contexto revela que la prosperidad de una persona o grupo social no puede realizarse más que a costa de otros. Es una especie de estado de la naturaleza hobbesiano, pero con disparidad de fuerzas, en la que la parte más endeble corre a cargo precisamente de los actores menos adaptables a los tiempos competitivos: los premodernos. Para resistir los avances, han tenido que recurrir a organizaciones de corte corporativo, que se antojaban cascarones vacíos al inicio de la transición.

Esos movimientos de resistencia al impulso neoliberal y, en general, al proceso modernizador han concitado crecientes simpatías por un sentido de justicia, ahondado en la tradición histórica de defensa de lo colectivo contra el embate individual. Los liberales se han olvidado que en el caso mexicano siempre que se han relajado los marcos jurídicos a favor de la libre iniciativa individual, el proceso ha desembocado en un abuso 
hacia los más débiles. Este sentido de justicia trasciende lo legal y evoca lo particular, tal y como lo han hecho los actores colectivos desde tiempos ancestrales. Tomemos dos ejemplos recientes que atestiguan su vigencia: en un contexto de disputa electoral para la presidencia de la república, el jefe de gobierno del Distrito Federal, que encabezaba las preferencias para los comicios de 2006, es desaforado a causa de haber incumplido la orden de un juez en torno a un predio expropiado por su gobierno. En sentido estricto, la medida judicial era legal y apelaba al sentido moderno de imperio sobre la ley; sin embargo, el sentido de justicia se apodera de buena parte de la sociedad mexicana hasta forzar la disculpa y el indulto presidencial. Otro más: en pleno uso de sus facultades legales, el gobierno de Vicente Fox decide expropiar tierras comunales, con la finalidad de construir un necesario aeropuerto. La comunidad reacciona violentamente y el decreto es revocado. Este tipo de ejemplos se multiplican, pero denuncian la imposibilidad de fincar la democracia en uno de sus principales pilares: el Estado de Derecho. El componente democrático se contrapone al liberal.

Otro de los actores premodernos -los grandes empresarios rentistashan sabido mantener, mediante relaciones con el poder político, los privilegios monopólicos u oligopólicos, que les ha permitido utilidades que combinan rendimientos del capital con la extracción de rentas. En un contexto de liberalización económica, esas estructuras de mercado acarrean reducciones en el excedente del consumidor, que vulneran el bienestar de la población, obstaculizan la competitividad y, por esta vía, las posibilidades de desarrollo. Pero lo importante para nuestros fines es que sus beneficiarios, en virtud de sus relaciones con el poder y del peso estratégico que ocupan en la economía nacional, registran una gran capacidad para negociar excepcionalidades a la ley, de la misma manera que lo hacen los grupos corporativos de raigambre popular, pero sin los contrapesos que imponía el Ejecutivo federal priista, en su afán de conservar los equilibrios políticos entre los factores de la producción.

Para determinar esta actitud hacia la ley, la encuesta inquirió una pregunta que trata de desvelar la separación entre lo justo y lo legal. Las respuestas se muestran en la gráfica III.

Como se puede apreciar, al considerar una medida injusta, sólo $29 \%$ la acataría, mientras que el resto buscaría no obedecerla o que no se aplicara al perjudicado, aunque haya sido armada democráticamente.

Por último, los gobernadores de los estados (provinciales) han devenido auténticos señores feudales -si se me permite la expresión, elocuente, pero no del todo acertada-, que buscan presupuesto y presencia nacional para aumentar su poder e influencia, en virtud de que la no reelección impide avanzar en sus carreras políticas en sus territorios y de que el sis- 


\section{Gráfica III}

Si en una junta de vecinos, la mayoría toma la decisión injusta y que lo perjudica a usted o a su familia, ¿̇obedecería la decisión, no la obedecería o pediría a la autoridad que la aplique a los demás pero no a usted?

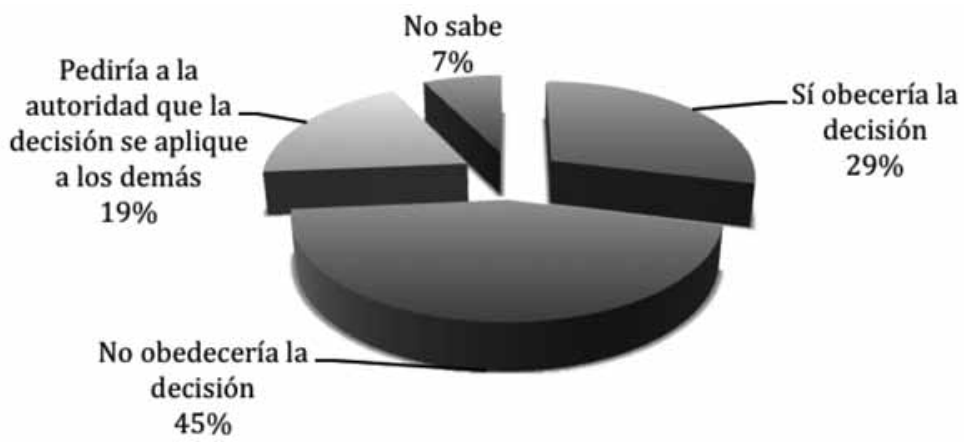

Fuente: Elaboración propia con datos de encuesta de Ávila et al. (2010).

tema de padrinazgo, que anteriormente apuntalaba el presidente de la república, está vedado para los ejecutivos locales de oposición, y muy limitado para los que militan en el partido en el gobierno. El mecanismo para aumentar esa influencia es la injerencia en el Congreso de la Unión, subordinando a diputados y senadores de su terruño, pero también a otros que pueden ver en ellos un respaldo para sus futuras biografías políticas.

\subsection{La autorreferenciación de la élite política}

$\mathrm{Al}$ abrirse espacio político al juego democrático, los partidos escasamente identificados con el agregado moderno de la sociedad, pugnaron por revivir sus huestes corporativas o arrebatárselas al otrora partido oficial. Las bases consensuales volvieron a redefinirse y a establecer un sistema dual: el ejecutivo y su fracción parlamentaria fincan su legitimidad en actores modernos (empresarios y clases medias), sin penetración en las masas populares; el PRI y el PRD combinaron este tipo de simpatías con actores de índole más tradicional. El consenso quedó fracturado y el país polarizado, como bien lo ejemplifican la elección del 2006, y más cotidianamente, la dificultad para alcanzar acuerdos, pues cuando éstos se logran, se plasman en normas legales de compromiso que atienden de manera cosmética los graves problemas que encara el país.

Así, se ha desarrollado una clase política autorreferenciada que depende muy poco de la ciudadanía y de la opinión pública. Por supuesto que este rasgo también podría describir la hegemonía priista, porque el presidente determinaba las carreras políticas. Sin embargo, hay dos diferen- 
cias importantes: bajo esa hegemonía el sistema era autoritario. En un escenario democrático, el sustrato ciudadano debería ser el que determina esos ascensos. La segunda diferencia, y quizá la más importante, es el hecho de que en el viejo sistema, el presidente podía castigar -y de hecho lo hacía- a quienes restaban legitimidad al sistema, especialmente cuando se le minaba mediante escándalos o cuando se perdía interlocución con segmentos determinados de la ciudadanía.

A estos hechos, se suma el determinante más importante de la autorreferenciación de la élite política: la partidocracia. Los partidos diseñaron las reglas que permiten acceder al campo de batalla por el poder; entre ellas, la prohibición de la reelección para gobernadores y de la no inmediata para legisladores, así como la invalidez de las candidaturas independientes garantizan la disciplina del partido, la dependencia de los políticos hacia sus institutos y la cerrazón a fuerzas competitivas alternativas. Ello genera que la batalla efectiva se despliegue entre tres partidos, mientras el resto juega a la recepción de prerrogativas monetarias que otorga la ley electoral. Incluso entre los tres primeros, la derrota salvaguarda puestos y dinero, que hacen llevaderos los descalabros electorales. Así una élite puede sobrevivir sin mayores penas cuando éstos se presentan.

Sin embargo, esta supervivencia es diferencial y depende de la capacidad de esos políticos para atrapar clientelas desmembradas del antiguo PRI y de movimientos populares emergentes. Por tal razón, la reavivación de los actores premodernos se vuelve indispensable para la vigencia de los políticos derrotados: no importa qué tantos votos acarrean a través de esas clientelas, sino qué tanto ayudan a movilizar personas en contra de iniciativas provenientes del gobierno. Esta proposición es avalada por la escasa proporción de los actores premodernos en el total de ciudadanos (15\%); porque sólo $7 \%$ de esta totalidad ha participado alguna vez en una marcha, y por el escaso grado de identificación partidista que muestra el cuadro 3.

Por otro lado, la partidocracia genera impunidades entre los integrantes de todos los partidos, que no se traducen en desventajas y ventajas electorales, debido precisamente a su carácter generalizado. Ello obedece a que los únicos que pueden castigar son los partidos; pero hacerlo significa reconocer faltas que podrían ser aprovechadas por sus rivales, especialmente en un contexto nacional, donde prácticamente hay elecciones locales todos los años. La conciencia de que ese diseño institucional no acarreará actos punitivos normaliza la generalización de prácticas reprobables, sin ningún miramiento a lo que piensen los ciudadanos. Su opinión deja de ser importante para los comicios, en virtud de que miembros de todos los partidos incurren en prácticas similares. Así, la clase política acaba por ser autorreferenciable. 


\subsection{Pérdida del poder central y su influencia sobre la calidad de la democracia}

¿Cuáles son las consecuencias estructurales del menoscabo del presidencialismo metaconstitucional y del reavivamiento de los actores premodernos sobre la calidad de la democracia? La más importante es la exhumación del dilema entre democracia y gobernabilidad, éste entrampó a los liberales del xix y a los revolucionarios del xx, que al final optaron por sacrificar aquel régimen en aras de reconstruir un Estado fuerte. Ahora la solución es distinta: se apuesta a una democracia que, a costa de debilitar el Estado, termina por ser acotada y estructuralmente deformada.

El presidencialismo metaconstitucional dotó al Ejecutivo federal de muchas facultades; destacó la de arbitraje sobre los agentes políticos y sociales, diseñada para generar y mantener equilibrios que garantizaran la estabilidad política y social. La literatura especializada ha enfatizado esta función en su dimensión más evidente: la política; sin embargo, se ha olvidado de la otra, que permitió lidiar con la heterogeneidad social. Para sortear los retos que a la gobernabilidad plantea la coexistencia de actores disímbolos, es preciso hacer politica con una dosis predominante de sensibilidad y entendimiento de las diferencias específicas entre los grupos y actores sociales. Ésta demanda cualidades personales que, a su vez, reclama el uso discrecional de la ley y del poder para atender situaciones que el imperio del derecho no puede resolver sin inyectar un sentimiento de injusticia en algunos de los afectados potenciales. El problema es que el uso de esas facultades meta $-y$ a veces contra- legales socava fuentes ineludibles del modelo cívico de la democracia, como el imperio de la ley y la renuncia a esquemas autoritarios. En dos ocasiones -el Porfiriato y los gobiernos revolucionarios- recurrieron a este mecanismo para gestar la estabilidad mediante la erección de un Estado fuerte-personalizado, en el primer caso, e institucionalizado, en el segundo-, que tuvo a la autoridad del Ejecutivo federal como piedra angular.

Fue ese presidencialismo el que resolvió los problemas de coordinación de elementos que, de otra manera, serían incoordinables por sus lógicas divergentes; es decir, solucionó los retos de governance, asociados a las tendencias históricas que condujeron reiteradamente a la dispersión del poder. La formación y consolidación del Estado nacional reclamó no sólo la eliminación de esos poderes, sino también -y más frecuentemente- su subordinación mediante negociaciones que implicaban la excepcionalidad de la ley (Guerra, 1980; Escalante, 1993 y 2006).

Las teorías de la modernización nos han enseñado que este proceso acarrea intenciones y resultados homogenizadores, a costa de tradiciones asentadas en diferenciaciones culturales e identitarias. Sin embargo, se 
olvidan que la democracia hace otro tanto: necesita uniformar para imponer una ley igual para todos. No es posible desarrollar una norma para cada grupo y, mucho menos, para cada persona. Es este sentido legal, el que funda las tendencias igualitarias de toda democracia $y$, si se me apura un poco, el que sustenta el principio de representatividad. En las sociedades predemocráticas y premodernas la legislación distingue entre grupos: nobles, siervos, corporaciones eclesiásticas y militares, comerciantes, etc. Así lo hacía la Corona española en la etapa colonial. Con todo su contenido liberal, el Porfiriato tuvo que emularla para apaciguar las continuas revueltas y lograr la estabilidad. Lo mismo sucedió con los gobiernos postrevolucionarios, que debieron acallar liderazgos locales asentados en diferencias regionales y movimientos sociales de índole muy disímbola, pero en ambos casos sin cambiar el carácter homogéneo de la ley: sólo era necesario su aplicación administrada. Esa dualidad entre formalidad y práctica jurídica fue el reflejo de los equilibrios entre actores modernos y premodernos.

El desvanecimiento del presidencialismo metaconstitucional y el debilitamiento del Poder Ejecutivo federal han traído consigo la pérdida de la capacidad de arbitraje de esa institución, y con ella, la de gestar equilibrios entre los actores sociales, porque simplemente se diluyó la coordinación (governance) que las hacía posible. Hoy los agentes políticos y esos actores actúan de forma independiente, acarreando costos elevadísimos para el desarrollo y obstáculos prácticamente infranqueables para el avance de la democracia, en la medida en que casi cualquier reforma institucional o disposición legal puede ser frenada o desobedecida por alguno de ellos, especialmente por los que sufragan la bandera de la premodernidad.

Pero también ha provocado la debilidad del Estado, y no solamente porque su fortaleza radicó en la presidencia de la república, sino también, y especialmente, por la ausencia de coordinación entre poderes, sean éstos fácticos o formales. Una democracia efectiva implica una redistribución del poder que evite su concentración en una instancia determinada; pero también supone la governance necesaria para que el Estado imponga la obediencia -y por tanto la gobernabilidad- que las leyes le permiten. Cuando esa governance se pierde, es imposible generar esa gobernabilidad. Los gobiernos y las instituciones mexicanas de la época democrática se han visto obligados a distorsionar la democracia, a fin de conservarla dentro de ciertos rangos mínimos. Por esta razón, considero que el resurgimiento de los actores colectivos es el factor más importante entre los que explican la desviación de la democracia de sus patrones más clásicos, porque es el que plasma de mejor manera la heterogeneidad social. 


\section{La presencia de los actores postmodernos}

El tercer factor que explica el resurgimiento de los actores colectivos es la importancia creciente de los actores postmodernos. Este contingente se nutre fundamentalmente por jóvenes urbanos, para quienes el futuro no es nada halagador; en ellos se ha desarrollado un acentuado individualismo regido por fines esencialmente hedonistas, así como una actitud de desembarazo de cualquier atadura de índole moral. Por ello, se desinteresan completamente por los procesos políticos y la ciudadanía es ejercida siempre como un derecho -especialmente de corte individual-, y rara vez como un deber.

$\mathrm{Su}$ indiferencia hacia los derechos civiles y su escasa participación en la esfera pública tiende a vaciar la democracia de otro potencial impulsor: defienden la individualidad, pero no están dispuestos a sacrificios que conduzcan esta defensa a la pugna por la ampliación de los derechos civiles. La incertidumbre en torno a su futuro más inmediato los atrapa en el goce del presente y en una postergación interminable del porvenir (Bauman, 2006; Durán y Nieto, 2007). Por ello no tienen intereses, sólo tienen simpatías. Cuando logran preocuparse por ella, la política se vuelve una actividad de consumo más que de inversión: no se arriesga nada y es posible gozar del placer de participar.

Son esas simpatías las que han condicionado su apoyo irrestricto y sin matices a los movimientos premodernos, desde el zapatismo hasta la lucha contra la alianza por la calidad educativa; el primero, sin duda legítimo; la segunda, una vil defensa del privilegio de los maestros de vender su plaza al termino de su vida laboral.

Es decir, el sentido de justicia contra la libre iniciativa individual y el neoliberalismo han cobrado la forma de una actitud mecánica y sin distinciones. Todo cabe en el saco del movimiento popular. Esta confusión es un factor que ha permitido que actores tan lejanos como los premodernos y postmodernos se encuentren en un imaginario justiciero, que atenta contra el imperio de la ley y el avance modernizador.

La importancia de los postmodernos radica en su creciente influencia en la opinión pública, que repliega -sin ser todavía predominante- la de los actores modernos. Se ha debilitado así el consenso a favor del paquete de medidas que vinculaban una economía liberal con un régimen democrático y promodernizador, frente a un pasado revindicado ahora no sólo por actores premodernos, sino también de índole postmoderna. Son éstos los que han abierto la puerta a los primeros para legitimar expansivamente sus posturas en los espacios de opinión pública, especialmente en los medios académicos y en lo que en México llamamos comentocracia, para referirse a los formadores profesionales de opinión. Si relacionamos a los 


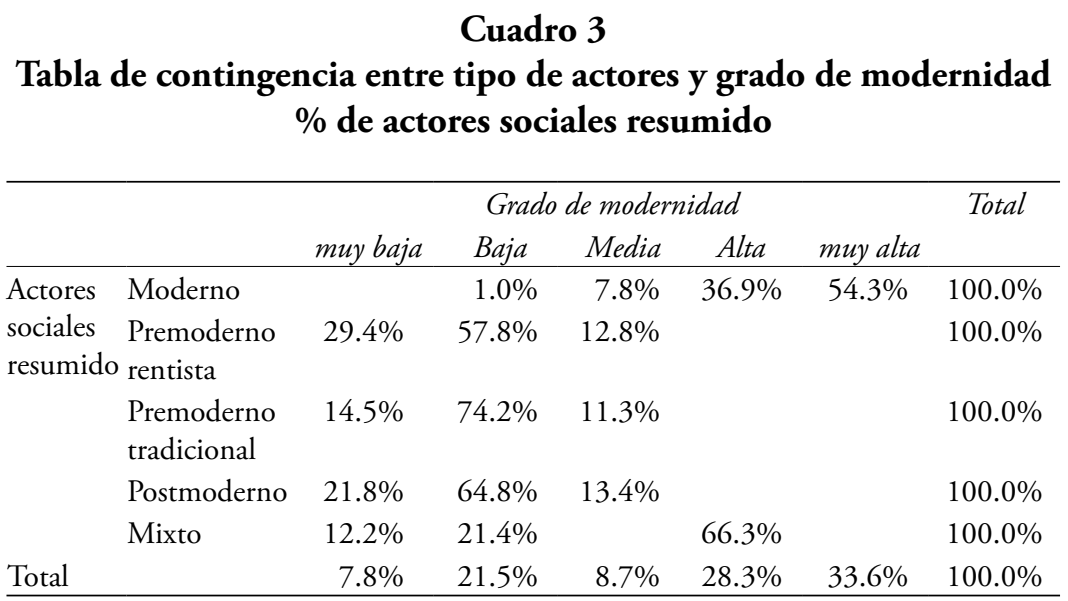

Fuente: Elaboración propia con datos de encuesta para elaborar el estudio de Ávila et al. (2010).

distintos actores con su grado de modernidad, podemos observar la afinidad entre las posiciones pre y postmodernas (cuadro 3). ${ }^{5}$

Como se puede observar, el grueso de los actores postmodernos (86\%) y de premodernos ( $87 \%$ de tradicionales; $88 \%$, de rentistas) se ubican en los rangos de baja y muy baja modernidad. En este sentido, se confirma la misma actitud. Adicionalmente, el cuadro anterior también nos dibuja una sociedad polarizada con relación al proyecto modernizador, en la que el elemento moderado -representado por los actores mixtos- representa una fracción insuficiente de ciudadanos para desempeñar el papel clave que paralelamente jugaron en otras transiciones hacia la democracia (Przeworski,1995; O’Donell y Schmitter, 1986). Ello inyecta pocas esperanzas a una transición gradual y negociada. Antes bien, torna asuntos estratégicos en clivages, que hoy dividen a los mexicanos: la inversión privada en el petróleo; la inclusión del IVA en alimentos y medicinas; la reforma laboral y otros aspectos de la modernización, en los que no hay puntos intermedios, sino posiciones radicales. En virtud del carácter mayoritario de los modernos, una de las formas de evitar que avance su posición es también acotar la democratización de las instituciones.

\section{Conclusiones}

El argumento central de este ensayo es que la democracia mexicana se encuentra estructuralmente detenida en una situación que la aleja del modelo clásico que opera en los países occidentales desarrollados, en virtud de que la heterogeneidad social impone dinámicas que constantemente ponen en juego la gobernabilidad, porque aquélla demanda niveles de

\footnotetext{
${ }^{5}$ Las pruebas chi cuadrada resultaron significativas para la tabla de contingencia.
} 
coordinación social que sólo pueden lograrse con la subordinación metalegal de poderes -emanados de esa misma heterogeneidad-que tienden a la autonomía y a la dispersión; es decir, al debilitamiento estructural del Estado como monopolio de la violencia legítima. Este obstáculo estructural ha desanimado a sus principales promotores -los actores modernos-, para quienes la democracia adquirió un carácter estrictamente instrumental para impulsar la modernización. La reacción de los opositores a este proceso ha sido detener el avance democrático como una forma de frenar el proceso de modernización, que amenaza privilegios gestados en las etapas autoritarias y que han recobrado su carta de legitimidad, tras el reavivamiento de los premodernos y el surgimiento de unos extraños aliados: los actores postmodernos. En este sentido, la alternancia partidista del año 2000 ha acarreado la autonomización de poderes locales y sociales. Esto no es nuevo en la historia de México; la novedad es el rasgo autorreferenciable de la élite política que propicia precisamente el carácter desviado, deficitario e interrumpido de nuestra pobre democracia.

\section{Apéndice}

\section{El indicador de pobreza}

Para construir una variable que mida la pobreza seguimos el método tradicional, basado en la línea de pobreza. La única modificación consiste en la estimación de la línea de la pobreza, que en lugar de calcular una para el medio urbano y otra para el rural, se calcula como un promedio ponderado de ambas, en las que el ponderador son las poblaciones de los dos ámbitos. La razón obedece a que la encuesta no permite distinguir quién de los encuestados habita en uno y en otro. Así, el Promedio Ponderado de las Líneas de Pobreza Rural y Urbana (PPLP) es el siguiente:

$$
P P L P=\alpha L P_{i}^{R}+(1-\alpha) L P_{i}^{U}
$$

El promedio ponderado de las líneas de la pobreza rural y urbana arroja estos resultados:

\section{Líneas de pobreza oficiales y promedio ponderado}

\begin{tabular}{lrrr}
\hline & Urbana & \multicolumn{1}{c}{ Rural } & \multicolumn{1}{c}{ PPLP } \\
\hline Alimentaria & $\$ 1,040.75$ & $\$ 773.65$ & $\$ 941.40$ \\
Capacidades & $\$ 1,276.47$ & $\$ 914.67$ & $\$ 1,141.90$ \\
Patrimonial & $\$ 2,088.14$ & $\$ 1,403.85$ & $\$ 1,833.63$ \\
\hline
\end{tabular}

Fuente: elaboración propia con datos de INEGI. Conteo de población y vivienda, 2005; Coneval, Líneas de pobreza, México: 2000-2009. 
Y el procedimiento se describe así:

$$
\begin{aligned}
X_{j} & =\frac{P P L P-Y P C H_{j}}{P P L P} \\
X_{j} & >0, \text { pobres } \\
X_{j} & <0, \text { no..pobres }
\end{aligned}
$$

Donde pplp es el promedio ponderado de las líneas de pobreza urbana y rural; $\alpha$, la proporción rural de la población total; $L P_{i}^{R}$, la línea de pobreza rural para la pobreza del tipo i (alimentaria, capacidades o patrimonial); ${ }^{6} L P_{i}^{U}$, línea de pobreza urbana; $\mathrm{YPCH}$, el ingreso per cápita del hogar donde vive el $\mathrm{j}$-ésimo encuestado. $\mathrm{X}$ es la brecha de la pobreza que mide la relativa entre PpLP y los ingresos del encuestado j-ésimo. $\mathrm{Si}$ esta brecha es positiva, éste puede ser considerado como pobre; si es negativa o igual a cero, como no pobre.

\section{El indicador de escolaridad}

Se trata de los ańos cursados y aprobados por el encuestado

\section{El grado de modernización}

(Expuesto arriba)

\section{Confianza}

Con relación al índice de confianza en las autoridades electas, se partió de la información que suministra la pregunta: "¿Qué tanto confía en...?”. Cada respuesta recibió un valor conforme a la siguiente tabla:

\begin{tabular}{lc}
\hline Totalmente & 10.00 \\
Mucho & 6.67 \\
Poco & 3.33 \\
Nada & 0.00 \\
\hline
\end{tabular}

El índice de confianza para cada rubro se construye conforme a la siguiente expresión:

${ }^{6}$ El gobierno mexicano distingue entre tres líneas de pobreza: la alimentaria, que es la que cubre una canasta para satisfacer las necesidades de alimentación; la de capacidades, que agrega los gastos de salud y educación, y la patrimonial, que adiciona a la de capacidades las erogaciones necesarias para transporte, vivienda y vestido. 


$$
I C_{j}=\frac{\sum_{i=0}^{10} f_{i j} * V R_{i}}{1200-D P}
$$

Donde ic es el índice de confianza para el rubro j-ésimo; f, la frecuencia o número de casos que asignan, de conformidad con la tabla anterior, el valor de respuesta (VR) i-ésima al rubro j-ésimo. DP, por su parte, son los datos perdidos. El índice de confianza total se consigue a estimar el promedio simple de los índices individuales.

\section{Representatividad}

(Expuesto arriba)

\section{Déficit en la gestión gubernamental}

La estimación de este déficit fue realizada en tres etapas: en la primera se pregunta al encuestado qué tan importantes son varias dimensiones del bienestar: economía, salud, armonía familiar, armonía social, educación, futuro de los hijos y libertad para realizar un proyecto de vida. Las respuestas opcionales son totalmente, mucho, poco, y, obviamente, nada. Como era de esperarse, las respuestas se concentran en las dos primeras (72\%). A continuación se esgrimen dos cuestionamientos: “QQué tanto puede hacer el gobierno para mejorar esas dimensiones?" y "¿qué tanto ha hecho el gobierno para mejorarlas?". La primera da cuenta de la capacidad del gobierno, y la segunda, de la forma en que utiliza esa capacidad en su ejercicio. Ello da lugar a una valorización de las siguientes respuestas:

\begin{tabular}{lclc}
\hline & $\begin{array}{c}\text { ¿Qué tanto puede } \\
\text { hacer el gobierno } \\
\text { por el bienestar } \\
(\text { CEB) }\end{array}$ & $\begin{array}{c}\text { ¿Qué tanto ha hecho } \\
\text { el gobierno por el } \\
\text { bienestar? }\end{array}$ & DEEB \\
\hline Totalmente & 10.00 & Mucho & 10 \\
Mucho & 6.67 & & 5 \\
Poco & 3.33 & Poco & 0 \\
Nada & 0 & Nada & \\
\hline
\end{tabular}

La tercera etapa consiste en estimar la brecha (absoluta: BA y relativa: BREB) entre lo que el gobierno puede hacer (СEB) y lo que hace (DEEB), según la percepción de los encuestados, bajo el siguiente procedimiento: 


$$
\begin{array}{r}
B A=C E B-D E E B \\
B R E B=\left[1-\left(\frac{D E E B}{C E B}\right)\right] * 100
\end{array}
$$

Este indicador de desempeño debe ser interpretado tanto por sus valores extremos como por sus intervalos, en virtud de que los valores de las respuestas de la tabla anterior no son equivalentes, aunque todos se inscriben en una misma escala. Por ejemplo mucho tiene un valor mayor en la primera pregunta, mientras que poco, tiene un valor inferior. Estas discrepancias nos sugieren medidas en ciertos rangos, más que valores puntuales. La escala es la siguiente:

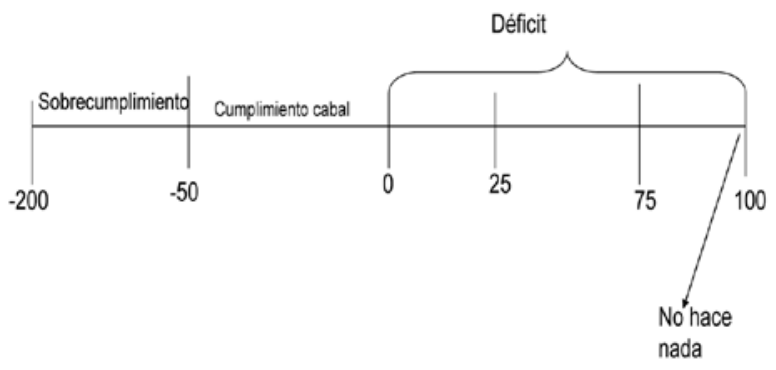

\section{Identificación partidista}

Cada una de las respuestas recibidas para detectar qué tan identificado está el encuestado con cada uno de los ocho partidos que pugnaron por una curul en la pasada elección federal (2009) recibió un valor que se mueve en una escala de 0 a 10; con ellas se puede construir no sólo un índice de identificación para cada partido, sino también uno general, si seguimos el siguiente procedimiento:

$$
I G I P_{i}=2 \operatorname{Max}\left(V R_{1, i}, V R_{2, i}, V R_{3, i}, V R_{4, i}, V R_{5, i}, V R_{6, i}, V R_{7, i}, V R_{8, i}\right)-\sum_{j=1}^{8} V R_{j, i}
$$

Donde IGPIP es el Índice General de Identificación Partidista del i-ésimo encuestado; VR, es el valor de su respuesta al j-ésimo partido, y Max indica, como es la costumbre, el valor máximo entre un conjunto de argumentos, en este caso el valor de las respuestas para cada partido. Al duplicarlo se pretende que la ecuación se transforme automáticamente en:

$$
I G P I_{i}=\operatorname{Max}\left(V R_{j}, . . V R_{8}\right)-\left(V R_{j}+. .+V R_{j+l-1}+V R_{j+l+1} \ldots .\right)
$$


De esta forma se persiguen dos propósitos: el central, que consiste en disminuir el valor máximo otorgado a un partido con los asignados a los demás; el técnico, que pretende que el valor máximo se conserve cuando es restado con la suma del total de valores que reciben todos los demás. El primero necesita una explicación adicional: cuando un encuestado reparte su fidelidad entre varios partidos, su identificación partidaria, aunque sea alta para uno de ellos, se diluye; por tanto, debe de ser disminuida con la suma de valores que asignó a los otros institutos políticos.

Sin embargo, al estimar la ecuación logística nos arrojó una relación negativa entre abstención y este determinante, que de alguna manera refleja lo estricto de esta definición y el rechazo que, en general, experimentan los partidos. Por tal razón, decidimos expresarla de esta manera:

$$
\begin{aligned}
& \operatorname{IGIP_{i}}=\operatorname{Max}\left(V R_{1, i}, V R_{2, i}, V R_{3, i}, V R_{4, i}, V R_{5, i}, V R_{6, i}, V R_{7, i}, V R_{8, i}\right) \\
& \sum_{j=1}^{8} V R_{j, i}-\operatorname{Max}\left(V R_{1, i}, V R_{2, i}, V R_{3, i}, V R_{4, i}, V R_{5, i}, V R_{6, i}, V R_{7, i}, V R_{8, i}\right)=0
\end{aligned}
$$

Es decir, soslayamos el valor que reciben los otros partidos.

\section{Sofisticación del votante}

Para captar la sofisticación del votante, entendida como grado de conocimiento de la política mexicana, se diseñó un grupo de cuatro preguntas de dificultad creciente. Con ello se pretende contar con una serie de variables proxy que, combinadas, den lugar a un índice de sofisticación para cada uno de los entrevistados. Los cuestionamientos inquieren sobre el partido al que pertenece el presidente de la república, el sindicato que lidera Elba Esther Gordillo (poderosa dirigente de los maestros), los grupos en conflicto en el Partido de la Revolución Democrática (PRD, partido de izquierda famoso por sus pugnas internas) y el número de elecciones para gobernador que coincidieron en 2009 con la elección federal. La estimación del índice de sofisticación siguió el siguiente procedimiento:

$$
I S_{j}=\left[\sum_{i=1}^{4} a_{i} X_{i}\right]^{*} 10
$$

Donde is es el índice de sofisticación del entrevistado j-ésimo, que se mueve en una escala de 0 a 10; X es la respuesta a la pregunta i-ésima, que pude asumir los siguientes valores: 
$X=1$, correcta

$X=0$, incorrecta

Por otro lado, fue necesario ponderar las respuestas para que reflejaran el grado de dificultad de forma escalada. Esta función la cumplen el grupo de ponderadores que denominamos con la letra $a$, que se calcularon como la proporción del total de respuestas incorrectas que corresponde al número de respuestas incorrectas a la pregunta i-ésima:

$$
a_{i}=\frac{\sum_{j=1}^{n} Y_{j}^{i}}{\sum_{j=1}^{n} Y_{j, i}}=\frac{Y_{1}^{i}+Y_{2}^{i}+\ldots+Y_{n}^{i}}{Y_{1,1}+Y_{2,1}+\ldots+Y_{n, 1}+Y_{1,2}+Y_{2,2}+\ldots+Y_{n, 2}+Y_{1,3}+\ldots Y_{n, 3}+Y_{1,4}+\ldots .+Y_{n, 4}}
$$

Donde $\mathrm{Y}$ es cada respuesta incorrecta a la pregunta i-ésima; n, el número de encuestados.

Al ponderar por las respuestas incorrectas, el coeficiente capta el grado de dificultad: mientras mayor es la proporción de desaciertos que obtiene una pregunta determinada entre el total de incorrecciones, más difícil es atinar en el ejercicio.

\section{Bibliografía}

Ávila, Marcela, Luis Alberto Morales, Henio Millán y Martha Gloria Morales (2010), Abstencionismo y participación electoral en México, Instituto Federal Electoral, edición digital, México.

Bauman, Zygmunt (2006), La modernidad líquida, Fondo de Cultura Económica, México.

Bourdieu, Pierre (1983), "Forms of capital”, en Hohn G. Richarson (comp.), Handbook of theory and research for the sociology of education, Greenwood Press, Nueva York, pp. 241-258.

Córdova, Arnaldo (1973), La política de masas del cardenismo, Era, México.

Durán-Barba, Jaime y Santiago Nieto (2007), Mujer, sexualidad, internet y política. Los nuevos electores latinoamericanos, Fondo de Cultura Económica, México. 
Escalante, Fernando (1993) Ciudadanos imaginarios, El Colegio de México, México.

Escalante, Fernando (2006), "México, fin de siglo" en José Antonio Aguilar et al., Pensar en México, Fondo de Cultura Económica, México.

Esping-Andersen, Gosta (1990), The three worlds of welfare capitalism, Princeton University Press, Princeton.

Guerra, Francois Xavier (1980), México: del antiguo régimen a la Revolución, Fondo de Cultura Económica, México.

Lin, Nan (2001), Social capital. A theory of social structure and accion, Cambridge University Press, Cambridge.

Lipovetsky, Gilles (2002), El Crepúsculo del deber. La ética indolora de los nuevos tiempos democráticos, Anagrama, Barcelona.

Millán-Valenzuela, Henio (1997), "Penetración de importaciones y dinamismo exportador”, Investigación Económica, 221, Universidad Nacional Autónoma de México, México, pp. 61-84.

Millán-Valenzuela, Henio (1998), Neoliberalismo y transición en México, El Colegio Mexiquense, A.C., Zinacantepec.

Millán-Valenzuela, Henio y Alejandro Natal (2008), "Un paseo por el subdesarrollo. Examen de las limitantes históricas de la accountability en México a través de un modelo de agencia", en Henio Millán y Alejandro Natal (coords.), Rendición de cuentas, democracia y sociedad civil en México, El Colegio Mexiquense, A.C., Zinacantepec.

North, Douglas (1989), Estructura y cambio en la historia económica, Fondo de Cultura Económica, México.

O’Donell, Guillermo y Philipe C. Schmitter (1986), Transitions from authoritarian rule: tentative conclusions about uncertain democracies, John Hopkins Univesity Press, Baltimore.

Polanyi, Karl (2001), The great transformation: the political and social origins of our time, Beacon Press, Boston. 
Przeworski, Adam (1995), Democracia y mercado, Cambrige University Press, Nueva York.

Roeder, Ralph (1973), Hacia el México moderno: Porfirio Díaz, Fondo de Cultura Económica, México.

Sennett, Richard (2000), La corrosión del carácter. Las consecuencias personales del trabajo en el nuevo capitalismo, Anagrama, Barcelona.

Womack, John Jr. (1979), Zapata y la Revolución mexicana, Siglo XxI, México.

Recibido: 18 de octubre de 2011. Reenviado: 20 de febrero de 2012. Reenviado: 13 de marzo de 2012. Aceptado: 16 de marzo de 2012.

Henio Millán-Valenzuela. Es doctor en ciencias sociales por la Universidad Iberoamericana. Actualmente es profesor-investigador de El Colegio Mexiquense, A.C. Es miembro del Sistema Nacional de Investigadores, nivel II. Sus líneas de investigación actuales son: democracia, pobreza y política social e instituciones y desarrollo. Entre sus últimas publicaciones destacan: "México: ¿hacia un nuevo modelo de desarrollo? Algunos elementos de juicio", Urbe. Revista Brasileira de Gestão Urbana, 3 (2), Pontifícia Universidade Católica do Paraná, Curitiba, pp. 273-291 (2011); "Elección racional, instituciones y cambio político", en Henio Millán, Martha Gloria Morales y Luis Fernández, Cambio político y déficit democrático en México, Porrúa-Universidad Autónoma de Querétaro, México, pp. 35-84 (2010); "Capital social y modernidad", Cátedra, año 10, 5, Universidad de Colima, Colima, pp. 3-23 (2009); Pobreza y microfinanzas. Una evaluación de impacto. El Colegio Mexiquense, A.C., Zinacantepec (2009); en coautoría con Alejandro Natal, "Un paseo por el subdesarrollo. Examen de los limitantes históricos de la accountability en México a través de un modelo de agencia”, en Henio Millán y Alejandro Natal (coords.), Rendición de cuentas, democracia y sociedad civil en México, El Colegio Mexiquense, A.C., Zinacantepec, pp. 65-116 (2008). 